\title{
Vulnerable COPD patients with comorbidities: the role of roflumilast
}

\author{
This article was published in the following Dove Press journal: \\ Therapeutics and Clinical Risk Management \\ 18 November 2014 \\ Number of times this article has been viewed
}

\author{
Melissa Lipari ${ }^{1,2}$ \\ Pramodini B Kale-Pradhan ${ }^{1,2}$ \\ 'Department of Pharmacy Practice, \\ Wayne State University; ${ }^{2}$ St John \\ Hospital and Medical Center, Detroit, \\ MI, USA
}

\begin{abstract}
Roflumilast is a selective phosphodiesterase-4 (PDE-4) inhibitor that was approved by the US Food and Drug Administration in February 2011 for the management of chronic obstructive pulmonary disease (COPD). Literature was retrieved through PubMed using the terms "roflumilast" and "COPD". Reference citations from publications identified were also reviewed. All articles published in English using the terms "roflumilast" and "COPD" were retrieved. For evaluation of clinical efficacy, published Phase III studies and pooled analyses of Phase III trials were included. In seven published Phase III trials, roflumilast at $500 \mu \mathrm{g}$ daily showed improvements in lung function as measured by pre- and post-bronchodilator forced expiratory volume in 1 second. Roflumilast appears to be useful in vulnerable patients who are at high risk for exacerbations. Roflumilast was found to be effective when administered alone and with concomitant long-acting bronchodilator therapy in the Caucasian and Asian population. Patients with severe-to-very severe COPD, chronic bronchitis, and frequent history of exacerbations derived the greatest benefit with roflumilast. Compared to the standard of care therapies, roflumilast is more cost-prohibitive. Roflumilast was well tolerated, with the most common adverse events observed in clinical trials being diarrhea, nausea, and headache. Weight loss and increased risk of psychiatric events have also been observed with roflumilast in clinical trials. Roflumilast is a safe and effective option for the treatment of COPD.
\end{abstract}

Keywords: roflumilast, COPD, phosphodiesterase-4 inhibitor

\section{Introduction}

The prevalence of chronic obstructive pulmonary disease (COPD) has been increasing over the last few decades and is a leading cause of morbidity and mortality worldwide. ${ }^{1}$ It was the sixth leading cause of death in 1990 and is expected to be the third leading cause of death by 2020. Acute COPD exacerbations are a leading cause of hospitalizations, associated with US\$29.5 billion in direct costs. The Global initiative for chronic Obstructive Lung Disease (GOLD) guidelines state that the strongest predictor for future exacerbations is a history of previous exacerbations. ${ }^{1}$ In addition, COPD commonly develops in middle-aged, long-time smokers, who may present with other comorbidities such as cardiovascular disease, osteoporosis, and skeletal muscle dysfunction. ${ }^{1}$ Such comorbidities may occur at any degree of airflow limitation. Moreover, worsening airflow limitation contributes to a higher risk for exacerbation and mortality, making these high-risk patients a vulnerable population.

The updated GOLD guideline classifies patients into four groups of severity based on spirometry, symptom severity, and exacerbation risk. Based on the severity of illness, several pharmacologic options are available to manage COPD. These include bronchodilators (beta-2 agonists, anticholinergics, and methylxanthines) and anti-inflammatory agents (inhaled and oral corticosteroids). In addition to the severity of illness, comorbidities need to be considered when developing a pharmacologic plan for the patient.
Correspondence: Pramodini B Kale-Pradhan Department of Pharmacy Practice,

Wayne State University and

St John Hospital and Medical

Center, 259 Mack Avenue,

Detroit, MI 4820I, USA

Tel + I 3133433943

Fax +I 3 I3 3437632

Email pkale@wayne.edu
Therapeutics and Clinical Risk Management 2014:10 969-976

969

Dovepress

http://dx.doi.org// 0.2147/TCRM.S55 105 (c) (i) (5) 2014 Lipari and Kale-Pradhan. This work is published by Dove Medical Press Limited, and licensed under Creative Commons Attribution - Non Commercial (unported, v3.0) permission from Dove Medical Press Limited, provided the work is properly attributed. Permissions beyond the scope of the License are administered by Dove Medical Press Limited. Information on how to request permission 
Lung function and symptoms improve with the use of these agents, and they may potentially reduce hospitalizations. ${ }^{1}$ However, these pharmacologic agents are not devoid of adverse effects and may worsen comorbid conditions. The phosphodiesterase (PDE)-4 inhibitor roflumilast (Daliresp ${ }^{\circledR}$ or Daxas ${ }^{\circledR}$ ) is a novel treatment alternative which targets inflammatory cells responsible for the progressive and persistent airflow limitation associated with COPD. This review article will evaluate the pharmacology, pharmacokinetics, and clinical efficacy and safety of roflumilast in vulnerable COPD patients. Literature was retrieved through PubMed using the terms "roflumilast" and "COPD". Reference citations from publications identified were also reviewed. All articles published in English using the terms "roflumilast" and "COPD" were retrieved.

\section{Vulnerable patients and COPD}

Approximately $30 \%$ of patients with COPD present with coexisting heart failure. ${ }^{2}$ In a prospective randomized trial, lung function in 107 patients with heart failure and COPD was compared to that of 377 patients with heart failure and no COPD. ${ }^{3}$ All patients' spirometric values were evaluated and reported as follows: forced expiratory volume in 1 second $\left(\mathrm{FEV}_{1}\right)$ was $65 \%$ of the predicted value $(95 \%$ confidence interval [CI]: 63\%-67\%); forced vital capacity (FVC) was $71 \%$ of predicted ( $95 \% \mathrm{CI}: 69 \%-72 \%$ ); and $\mathrm{FEV}_{1} / \mathrm{FVC}$ was 0.72 (95\% CI: $0.71-0.73)$. All three of these indicators were strong predictors of all-cause mortality in these patients. Patients with moderate-to-severe COPD had a shorter survival rate when compared with patients without $C O P D$ or with mild COPD $(P=0.004)$. As there is an overlap of common symptoms such as breathlessness with COPD and heart failure, patients with these conditions may not be optimally treated. This may place patients at risk for negative outcomes.

Since patients commonly present with concomitant cardiovascular disease, beta-blockers may be a part of their therapeutic regimen. ${ }^{4,5}$ Beta-blockers have been shown to be beneficial in cardiac disease. However, in patients with COPD, nonselective beta-blockers may be life-threatening due to bronchoconstriction. ${ }^{6}$ Three recent studies investigated the safety of beta-1-selective antagonists in patients with COPD. The first study was a Cochrane Review which assessed the effect of beta-1-selective antagonists on $\mathrm{FEV}_{1}$ at rest in patients with COPD versus placebo. ${ }^{7}$ It was found in 22 randomized, blinded, controlled studies (eleven single-dose treatment and eleven long-term treatment) that beta-1-selective antagonists produced no difference in $\mathrm{FEV}_{1}$ or resulted in adverse respiratory effects. This was consistent in patients with either severe or reversible obstruction. A second randomized, placebocontrolled, crossover trial investigated the effects of beta-1 -selective antagonists on dynamic hyperinflation in patients with moderate-to-severe COPD. ${ }^{8}$ The investigators compared bisoprolol to placebo and assessed the extent of dynamic hyperinflation at peak isotime during a two-cycle endurance test. Peak isotime was defined as the latest time point that was reached during the exercise test. Although bisoprolol resulted in modest worsening of dynamic hyperinflation, exercise duration did not change with moderate-to-severe COPD. The investigators concluded that the effect on hyperinflation was small and should not be a contraindication for bisoprolol therapy in COPD. Lastly, a retrospective cohort of patients hospitalized for acute COPD exacerbation with concomitant therapy for ischemic heart disease or congestive heart failure were used in a study to evalutate effects on hospital mortality, 30-day readmission, and late mechanical ventilation. ${ }^{9}$ The investigators showed that there was no association between beta-1-selective antagonist therapy and the three endpoints studied. Therefore, continuing beta-1-selective antagonists appears to be safe in hospitalized patients with COPD and concomitant heart failure OR ischemic heart disease.

Osteoporosis is another common comorbid condition in patients with COPD. ${ }^{1}$ Systemic inflammation secondary to moderate-to-severe COPD may lead to osteoporosis. ${ }^{10}$ Three studies have assessed the effect of inhaled corticosteroids (ICS) (triamcinolone, budesonide, and fluticasone) on bone mineral density in patients with COPD. ${ }^{11-13}$ Although triamcinolone was associated with a decrease in bone mineral density at 3 years from baseline, bone mineral density did not change with inhaled fluticasone and budesonide. On the other hand, a significant risk of osteoporosis with systemic corticosteroids has been established.

In addition, prolonged oral corticosteroid use may result in peripheral and respiratory muscle weakness. One study investigated 21 patients admitted for asthma or COPD exacerbation requiring dose escalation of oral corticosteroids. ${ }^{14}$ The study found that patients with COPD or asthma had respiratory and peripheral muscle weakness attributed to treatment with even low doses of corticosteroids. The outcome of muscle weakness was independent of airflow obstruction. A second study investigated eight patients with COPD and concomitant steroid-induced myopathy compared to control. ${ }^{15}$ Patients with steroid-induced myopathy had greater peripheral and ventilatory muscle weakness compared to control $(P<0.001)$. Patients in the steroid-induced myopathy group had a decreased survival rate compared to control patients, with a similar level of airflow limitation $(P<0.025)$. 


\section{Safety and special dosing considerations}

In clinical trials involving 4,438 patients with COPD, the most common adverse events with roflumilast were diarrhea (9.5\%), weight loss $(7.5 \%)$, nausea $(4.7 \%)$, and headache (4.4\%). Rates of discontinuation due to adverse events were $14.8 \%$ with roflumilast and $9.9 \%$ with placebo, most commonly due to diarrhea and nausea. ${ }^{16}$

Weight loss is common in patients with severe COPD and is an independent risk factor for mortality. ${ }^{1}$ The exact mechanism is not known, but is thought to be due to fat loss, as PDE is involved in lipolysis. ${ }^{17}$ Weight loss was reported in $7.5 \%$ compared to $2.1 \%$ in the roflumilast and placebo groups, respectively, with an average weight loss of $2 \mathrm{~kg} .1,16$ In a pooled analysis, patients experiencing gastrointestinal effects had greater weight loss, particularly in the first 6 months. ${ }^{18}$ Therefore, this drug should be avoided in underweight patients. ${ }^{1}$

Psychiatric events such as insomnia, anxiety, and depression have been observed more commonly with roflumilast. ${ }^{16}$ Three patients attempted suicide, with one of the three completing suicide, in clinical trials. Caution is advised in patients with a history of depression and/or suicidal behavior or thoughts.

Roflumilast $250 \mu \mathrm{g}$ once daily was studied in patients with hepatic impairment for 14 days. ${ }^{19}$ There were eight patients in each classification (Child-Pugh class A, B and healthy subjects). Results showed the area under the curve (AUC) of roflumilast increased by $51 \%$ and roflumilast $\mathrm{N}$-oxide by $24 \%$ with mild impairment (Child-Pugh class A). Similarly, there was an increase in roflumilast and roflumilast $\mathrm{N}$-oxide of $92 \%$ and $41 \%$, respectively, in Child-Pugh class B patients. In addition, there was an increase in $\mathrm{C}_{\max }$ of roflumilast and roflumilast $\mathrm{N}$-oxide of $2 \%$ and $26 \%$, respectively, in Child-Pugh class A and of $27 \%$ and $40 \%$, respectively, in Child-Pugh class B. The manufacturers of roflumilast do not recommend its use in patients with Child-Pugh class B and C. ${ }^{16}$ Further, a dose of $500 \mu \mathrm{g}$ has not been studied in patients with hepatic impairment.

In addition, roflumilast $500 \mu \mathrm{g}$ was investigated in 12 patients with severe renal impairment, defined as a creatinine clearance $<30 \mathrm{~mL} / \mathrm{min}^{20}$ In patients with renal impairment, roflumilast's $\mathrm{AUC}$ and $\mathrm{C}_{\max }$ concentrations were decreased by $20 \%$ and $16 \%$, respectively, compared to healthy subjects. Roflumilast $\mathrm{N}$-oxide's AUC and $\mathrm{C}_{\max }$ were also decreased, by $16 \%$ and $12 \%$, respectively, in patients with renal impairment compared to healthy subjects. Halflife concentrations of roflumilast and roflumilast $\mathrm{N}$-oxide increased by $19 \%$ and $30 \%$, respectively, in patients with severe renal impairment versus healthy subjects. Therefore, no dosage adjustments are needed for patients with renal impairment. ${ }^{16}$

\section{Overview of pharmacology}

Eleven PDEs make up the PDE super-family and are responsible for various biologic functions. ${ }^{21}$ PDE-4 inactivates secondary messenger cyclic adenosine monophosphate found in proinflammatory and immune-competent cells in the lungs. Roflumilast and its active metabolite (roflumilast $\mathrm{N}$-oxide) are selective PDE-4 inhibitors that result in anti-inflammatory effects by preventing the breakdown of cyclic adenosine monophosphate, allowing it to activate protein kinase A. $\cdot^{16,17}$ Inhibition of fibrotic lung remodeling and decreased oxidative stress are achieved by reducing the release of inflammatory mediators from neutrophils, monocytes, and cytokines from CD-8 and CD-4 T-cells. In healthy subjects, it has been demonstrated that roflumilast may reduce the number of neutrophils, other inflammatory cells, and inflammatory markers in the sputum and bronchial airways. ${ }^{22,23}$

The absolute bioavailability of roflumilast following oral administration is $79 \% .{ }^{24}$ The time of peak plasma concentrations is about 1 hour, while steady-state concentrations are achieved in about 3 to 4 days following once-daily dosing. Roflumilast exhibits a linear and predictable pharmacokinetic profile over doses ranging from 250 to $1,000 \mu \mathrm{g} .{ }^{17}$

Roflumilast is rapidly metabolized to an active metabolite, roflumilast $\mathrm{N}$-oxide, via CYP3A4 and CYP1A2 metabolism. Roflumilast N-oxide accounts for approximately $90 \%$ of the total PDE-4 inhibitory activity and exhibits similar potency and specificity to the parent compound. ${ }^{17}$ Peak plasma concentrations of the active metabolite are reached in 8 hours, and steady-state plasma concentrations are reached within 6 days. Approximately $70 \%$ of roflumilast is excreted renally.

Administration of roflumilast in a non-fasting state reduces the $\mathrm{C}_{\max }$ and time to peak plasma concentration of the parent compound by $40 \%$ and 1 hour, respectively, in healthy subjects. ${ }^{25}$ Roflumilast $\mathrm{N}$-oxide, which is primarily responsible for pharmacological activity, is not affected by a fasting or nonfasting state. Therefore, roflumilast can be taken with or without food. ${ }^{16}$ Roflumilast is highly protein bound (99\%), with a half life of 17 hours. Steady state concentrations are achieved at 3-4 days. It is metabolized by CYP3A4 and CYP1A2 to roflumilast $\mathrm{N}$-oxide. It is renally eliminated. Roflumilast $\mathrm{N}$-oxide is also highly protein bound (97\%) with a half life of 30 hours. Steady state concentrations are reached at 6 days. It is metabolized by CYP3A4 and renally eliminated. ${ }^{16}$ 


\section{Clinical efficacy}

Roflumilast was evaluated for clinical efficacy in seven Phase III, randomized, double-blind, placebo-controlled, multicenter trials as monotherapy and in combination therapy in patients with varying degrees of COPD severity (Table 1). ${ }^{18,26-29}$ Three of the seven trials showed that roflumilast significantly increased FEV ${ }_{1}$ compared to placebo. ${ }^{26-28}$ Rates of exacerbation were also significantly lower in the roflumilast arm. There are several limitations to the above trials. The first trial's short duration makes it difficult to determine long-term improvements in lung function, health-related quality of life, and exacerbation rates. ${ }^{26}$ As well, patients were unable to continue long-acting maintenance medications, therefore roflumilast's effectiveness in addition to maintenance medications could not be assessed. Similarly to the first trial, patients taking longterm bronchodilator therapy in the second trial and patients taking concomitant ICS in the third trial were excluded. ${ }^{27,28}$ Therefore, the clinical significance of adding roflumilast in patients with severe or very severe disease is difficult to ascertain, as such patients are more likely to be taking longterm bronchodilator therapy in addition to ICS.

A post hoc pooled analysis of the 2007 trial combined with a previously unpublished study evaluated a total of 2,690 patients with chronic bronchitis with or without emphysema, or those taking concomitant ICS or using short-acting anticholinergics, and with high cough or sputum scores. In this study, roflumilast showed a trend toward reducing exacerbation rates in patients. ${ }^{18}$

Two Phase III, 6-month, randomized, double-blind, placebo-controlled, multicenter trials assessed the benefit of adding roflumilast to long-acting bronchodilators in patients with moderate-to-severe COPD ${ }^{29}$ In the first study, 933 patients were randomized to receive roflumilast $500 \mu \mathrm{g}$ plus salmeterol (long-acting beta agonist [LABA]) or placebo plus salmeterol, while 743 patients in the second study were randomized to receive roflumilast $500 \mu \mathrm{g}$ plus tiotropium or placebo plus tiotropium. FEV improved significantly compared to placebo in both trials. Rates of exacerbations were not significantly different in either of the studies; however, the proportion of patients experiencing moderate or severe exacerbations was significantly reduced in the salmeterol study but not in the tiotropium study. Limitations of this study include the short duration and insufficient power to assess secondary outcomes. In addition, a majority of the patients in both studies had moderate COPD and thus were at a lower risk for exacerbations.

An additional prespecified pooled analysis in 3,091 patients with a frequent exacerbation history was conducted to assess the efficacy of roflumilast used concomitantly with LABA in reducing exacerbation frequency. ${ }^{30}$ Mean rate of exacerbations was significantly reduced regardless of LABA use. Roflumilast also significantly reduced mean rate of exacerbations regardless of exacerbation history. The main limitation of this study is that it cannot be extrapolated to those patients on concomitant LAACs. Additionally, subgroup analyses regarding exacerbation frequency were not prespecified, and outpatient records documenting exacerbations may have been incomplete.

Roflumilast $500 \mu \mathrm{g}$ once daily was compared to placebo in 410 Asian patients over 12 weeks. ${ }^{31}$ Roflumilast significantly improved $\mathrm{FEV}_{1}$ in patients with moderate-to-severe COPD. The treatment was well tolerated in this population. Further, the adverse effects were similar to those found in the Caucasian population. In another recent study, the efficacy and safety of roflumilast was determined in predominantly ethnic Chinese patients. ${ }^{32}$ Three hundred and thirteen patients were randomized in a double-blind fashion to either roflumilast $500 \mu \mathrm{g}$ or placebo. Roflumilast significantly increased $\mathrm{FEV}_{1}$ in these patients. The adverse effect rates were similar to those previously reported in the literature. These studies demonstrated that the efficacy of roflumilast is similar in the Asian compared to the Caucasian population.

A recent meta-analysis of roflumilast found a significant reduction in moderate-to-severe exacerbations and improvement in pre-bronchodilator $\mathrm{FEV}_{1}$ compared to placebo. ${ }^{33}$ However, the investigators did not find a significant reduction in severe exacerbations or mortality.

In addition, the REACT study is an ongoing 1-year, Phase III/IV, randomized, double-blind, multicenter trial designed to investigate if roflumilast can further reduce exacerbation rates and improve lung function when added to a fixed combination of LABA and ICS ${ }^{34}$ Roflumilast's role in high-risk patients may be further defined by the results of this study. This study may provide further information on the quality of life issue in the vulnerable population or patients with high risk.

\section{Cost-effectiveness}

The cost-effectiveness of roflumilast was evaluated in three different studies conducted in the United Kingdom. The first cost-effectiveness study of roflumilast was in 1,505 patients with severe or very severe COPD. This study analyzed data from a 1-year, randomized, placebo-controlled, double-blind, multinational trial of roflumilast $500 \mu \mathrm{g}$ once daily. ${ }^{35}$ There were 159 centers from 14 countries included in this trial. Costs were analyzed from a societal perspective and included 


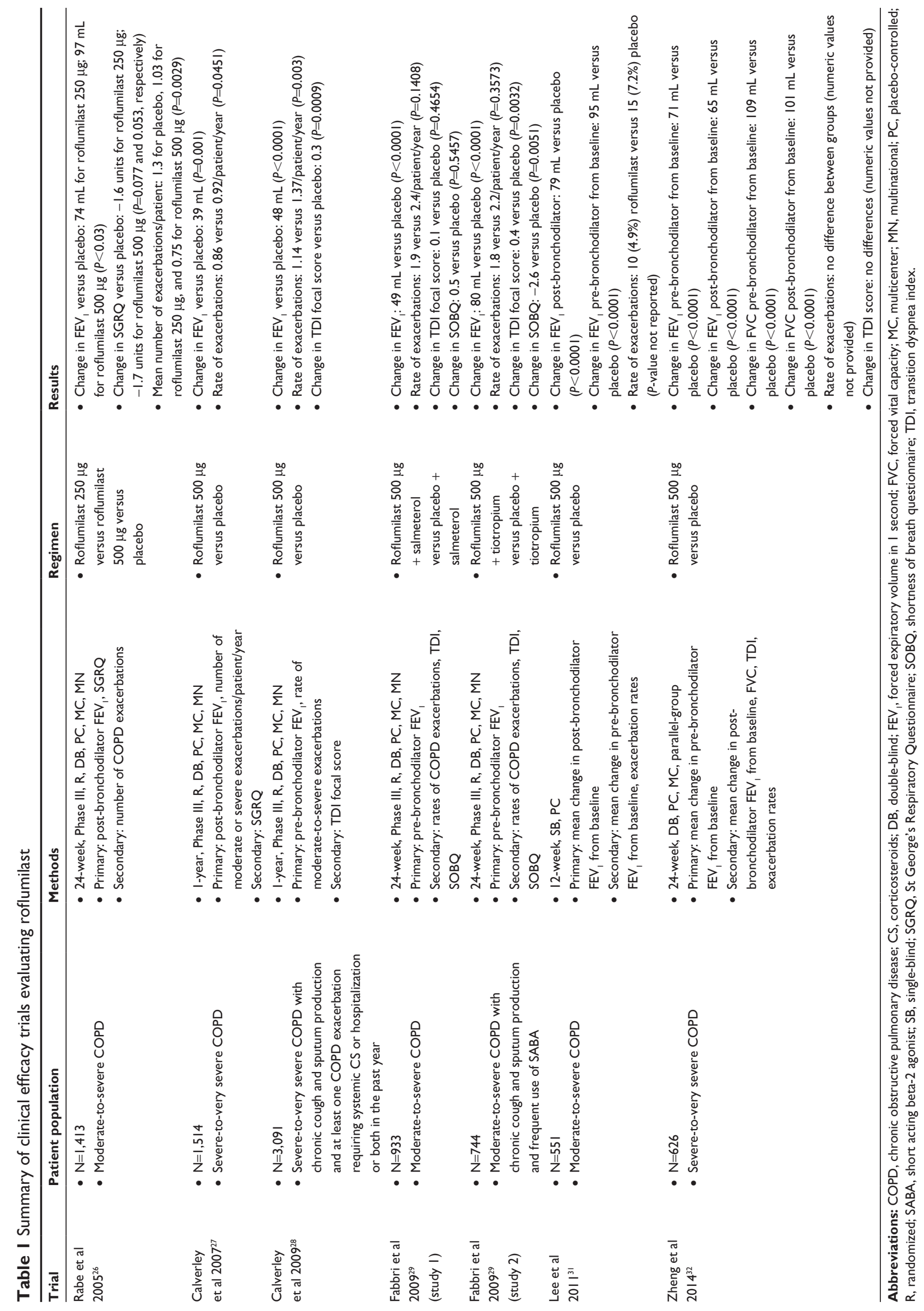


direct health care costs and productivity losses due to absence from work. The study also assessed the total number of patients with an improvement of a minimum of four units on the St George's Respiratory Questionnaire (SGRQ) score and the incremental cost associated with the difference in the number of moderate-to-severe exacerbations. Estimated costs were derived from 2004 UK pricing. Total COPD-related costs were $£ 1,636.74$ (approximately US\$2,261.32) for roflumilast compared to $£ 1,401.16$ (US\$1,935.84) for placebo. There was a 0.05 -unit (95\% CI: -0.05 to 0.15$)$ increase in the number of patients with a $\geq 4$-unit improvement of the SGRQ total score. As well, the mean number of moderate or severe exacerbations decreased by 0.10 (95\% CI: -0.05 to 0.26 ), or $9 \%$, which was not statistically significant. The cost avoided per exacerbation and the cost per clinically relevant improvement in SGRQ was £2,356 (US\$3,255) and $£ 4,712$ (US\$6,510), respectively. A subgroup analysis of patients with very severe COPD showed net cost savings compared to placebo. This study is limited, as roflumilast was only compared to placebo and the overall rate of exacerbations was low, which might have underestimated roflumilast's ability to lower exacerbations rates.

The second cost-effectiveness study evaluated patients with severe COPD being treated with various combinations of a long-acting muscarinic antagonist, a LABA, an ICS, and roflumilast. ${ }^{36}$ The study defined efficacy as the relative rate ratios of COPD exacerbations. Costs were calculated from the perspective of the UK National Health Service and included total costs. Patients able to take ICS were analyzed separately from those who were unwilling or intolerant to ICS. Long-acting muscarinic antagonist was shown to be more cost-effective as initial treatment for patients tolerant to ICS. LAAC + LABA/ICS was more cost-effective than LABA/ICS + roflumilast in those who required additional therapy due to exacerbations. Among patients in the ICSintolerant group, LABA or LAAC was preferred as initial therapy. Among patients who were intolerant to ICS and still experiencing exacerbations, LABA + LAAC was preferred over LABA + LAAC + roflumilast.

The third study determined the cost-effectiveness of adding roflumilast to LABA in patients with severe-to-very severe COPD. ${ }^{37}$ The investigators found that concomitant use of roflumilast with LABA increased quality-adjusted life years from 5.45 to $5.61(0.16$ [95\% CI: $0.02-0.31$ ] quality-adjusted life years gained) at a cost of $£ 3,197(95 \%$ CI: 2,135-4,253) or 5,408.63 (95\% CI: 3,611.96-7,195.16) in US dollars.
Treatment options based on GOLD guidelines for patients with severe and very severe COPD include the addition of ICS to LABA either with or without an LAAC. ${ }^{38}$ Average wholesale prices for a 30-day supply of ICS include $\$ 135$ for fluticasone and $\$ 152$ for budesonide. ${ }^{39}$ Average wholesale prices for a 30-day supply of long-acting bronchodilators include $\$ 157$ for salmeterol, \$265 for formoterol, and \$337 for tiotropium. The actual wholesale price per unit of roflumilast is US\$9.40, which translates to US\$282 for a 30-day supply of therapy.

\section{Place in therapy}

Roflumilast has been shown to be effective in improving lung function and decreasing COPD exacerbations which are typically associated with the vulnerable patient population. However, it is important to consider both the pros and cons of roflumilast to determine its role in COPD treatment. Unlike most COPD therapies, roflumilast is available as an oral tablet, which may improve adherence in these patients. However, roflumilast has several disadvantages, including potential for drug interactions, adverse effects, and high cost, which may limit its use. Additionally, roflumilast is associated with weight loss and psychiatric events and is contraindicated in moderate-to-severe hepatic impairment. Cost is an important limitation, as roflumilast is more expensive than ICS and LABA. All of these factors need to be considered when weighing the risks and benefits of starting roflumilast in each patient.

\section{Conclusion}

Roflumilast was shown to be safe and effective in several Phase III, randomized, double-blind, and placebo-controlled multicenter trials in different ethnic populations. In general, roflumilast appears to be useful in vulnerable patients with moderate-to-severe disease who are at high risk for exacerbations. However, the risks and benefits must be weighed when initiating roflumilast.

\section{Disclosure}

The authors report no conflicts of interest in this work.

\section{References}

1. Global Strategy for the Diagnosis, Management, and Prevention of Chronic Obstructive Pulmonary Disease. Global Initiative for Chronic Obstructive Lung Disease; 2014. Available from: http://www.goldcopd. org/uploads/users/files/GOLD_Report_2014_Jun11.pdf. Accessed August 11, 2014.

2. Rutten FH, Cramer MJ, Grobbee DE, et al. Unrecognized heart failure in elderly patients with stable chronic obstructive pulmonary disease. Eur Heart J. 2005;26(18):1887-1894. 
3. Iversen KK, Kjaergaard J, Akkan D, et al; ECHOS Lung Function Study Group. The prognostic importance of lung function in patients admitted with heart failure. Eur J Heart Fail. 2010;12(7):685-691.

4. Yancy CW, Jessup M, Bozkurt B, et al. 2013 ACCF/AHA guideline for the management of heart failure: executive summary: a report of the American College of Cardiology Foundation/American Heart Association Task Force on practice guidelines. Circulation. 2013;128(16): 1810-1852.

5. Fihn SD, Gardin JM, Abrams J, et al; American College of Cardiology Foundation; American Heart Association Task Force on Practice Guidelines; American College of Physicians, et al. 2012 ACCF/AHA/ACP/ AATS/PCNA/SCAI/STS Guideline for the diagnosis and management of patients with stable ischemic heart disease: a report of the American College of Cardiology Foundation/American Heart Association Task Force on Practice Guidelines, and the American College of Physicians, American Association for Thoracic Surgery, Preventive Cardiovascular Nurses Association, Society for Cardiovascular Angiography and Interventions, and Society of Thoracic Surgeons. J Am Coll Cardiol. 2012;60(24):e44-e164.

6. Westfall TC, Westfall DP. Adrenergic agonists and antagonists. In: Brunton LL, Chabner BA, Knollmann BC, editors. Goodman \& Gilman's The Pharmacological Basis of Therapeutics. 12th ed. New York, NY: The McGraw-Hill Companies; 2011:277-355.

7. Salpeter S, Ormiston T, Salpeter E. Cardioselective beta-blockers for chronic obstructive pulmonary disease. Cochrane Database Syst Rev. 2005;(4):CD003566.

8. Mainguy V, Girard D, Maltais F, et al. Effect of bisoprolol on respiratory function and exercise capacity in chronic obstructive pulmonary disease. Am J Cardiol. 2012;110(2):258-263.

9. Stefan MS, Rothberg MB, Priya A, Pekow PS, Au DH, Lindenauer PK. Association between $\beta$-blocker therapy and outcomes in patients hospitalised with acute exacerbations of chronic obstructive lung disease with underlying ischaemic heart disease, heart failure or hypertension. Thorax. 2012;67(11):977-984.

10. Madsen H, Brixen K, Hallas J. Screening, prevention and treatment of osteoporosis in patients with chronic obstructive pulmonary disease - a population-based database study. Clin Respir J. 2010;4(1):22-29.

11. Lung Health Study Research Group. Effect of inhaled triamcinolone on the decline in pulmonary function in chronic obstructive pulmonary disease. N Engl J Med. 2000;343(26):1902-1909.

12. Ferguson GT, Calverley PM, Anderson JA, et al. Prevalence and progression of osteoporosis in patients with COPD: results from the TOwards a Revolution in COPD Health study. Chest. 2009;136(6): 1456-1465.

13. Pauwels RA, Löfdahl CG, Laitinen LA, et al. Long-term treatment with inhaled budesonide in persons with mild chronic obstructive pulmonary disease who continue smoking. European Respiratory Society Study on Chronic Obstructive Pulmonary Disease. $N$ Engl J Med. 1999;340(25):1948-1953.

14. Decramer M, Lacquet LM, Fagard R, Rogiers P. Corticosteroids contribute to muscle weakness in chronic airflow obstruction. Am J Respir Crit Care Med. 1994;150(1):11-16.

15. Decramer M, de Bock V, Dom R. Functional and histologic picture of steroid-induced myopathy in chronic obstructive pulmonary disease Am J Respir Crit Care Med. 1996;153(6 Pt 1):1958-1964.

16. Daliresp ${ }^{\circledR}$ (roflumilast) tablets [prescribing information]. Oranienburg: Nycomed GmbH; 2011. Available from: http://www.accessdata. fda.gov/drugsatfda_docs/label/2011/022522s000lbl.pdf. Accessed August 11, 2014

17. Rabe KF. Update on roflumilast, a phosphodiesterase 4 inhibitor for the treatment of chronic obstructive pulmonary disease. $\mathrm{Br} J$ Pharmacol. 2011;163(1):53-67.

18. Rennard SI, Calverley PM, Goehring UM, Bredenbroker D, Martinez FJ. Reduction of exacerbations by the PDE4 inhibitor roflumilast - the importance of defining different subsets of patients with COPD. Respir Res. 2011;12:18.
19. Hermann R, Nassr N, Lahu G, et al. Steady-state pharmacokinetics of roflumilast and roflumilast $\mathrm{N}$-oxide in patients with mild and moderate liver cirrhosis. Clin Pharmacokinet. 2007;46(5):403-416.

20. Bethke TD, Hartmann M, Hünnemeyer A, Lahu G, Gleiter CH. Influence of renal impairment on the pharmacokinetics of oral roflumilast: an open-label, parallel-group, single-center study. Int J Clin Pharmacol Ther. 2011;49(8):491-499.

21. Page CP, Spina D. Selective PDE inhibitors as novel treatments for respiratory diseases. Curr Opin Pharmacol. 2012;12(3):275-286.

22. Hatzelmann A, Morcillo EJ, Lungarella G, et al. The preclinical pharmacology of roflumilast - a selective, oral phosphodiesterase 4 inhibitor in development for chronic obstructive pulmonary disease. Pulm Pharmacol Ther. 2010;23(4):235-256.

23. Grootendorst DC, Gauw SA, Verhoosel RM, et al. Reduction in sputum neutrophil and eosinophil numbers by the PDE4 inhibitor roflumilast in patients with COPD. Thorax. 2007;62(12):1081-1087.

24. Hohlfeld JM, Schoenfeld K, Lavae-Mokhtari M, et al. Roflumilast attenuates pulmonary inflammation upon segmental endotoxin challenge in healthy subjects: a randomized placebo-controlled trial. Pulm Pharmacol Ther. 2008;21(4):616-623.

25. Hauns B, Hermann R, Hünnemeyer A, et al. Investigation of a potential food effect on the pharmacokinetics of roflumilast, an oral, once-daily phosphodiesterase 4 inhibitor, in healthy subjects. J Clin Pharmacol. 2006;46(10):1146-1153.

26. Rabe KF, Bateman ED, O'Donnell D, Witte S, Bredenbröker D, Bethke TD. Roflumilast - an oral anti-inflammatory treatment for chronic obstructive pulmonary disease: a randomised controlled trial. Lancet. 2005;366(9485):563-571.

27. Calverley PM, Sanchez-Toril F, McIvor A, Teichmann P, Bredenbroeker D, Fabbri LM. Effect of 1-year treatment with roflumilast in severe chronic obstructive pulmonary disease. Am J Respir Crit Care Med. 2007;176(2):154-161.

28. Calverley PM, Rabe KF, Goehring UM, Kristiansen S, Fabbri LM, Martinez FJ; M2-124 and M2-125 study groups. Roflumilast in symptomatic chronic obstructive pulmonary disease: two randomised clinical trials. Lancet. 2009;374(9691):685-694.

29. Fabbri LM, Calverley PM, Izquierdo-Alonso JL, et al; M2-127 and M2-128 study groups. Roflumilast in moderate-to-severe chronic obstructive pulmonary disease treated with longacting bronchodilators: two randomised clinical trials. Lancet. 2009;374(9691): 695-703.

30. Bateman ED, Rabe KF, Calverley PM, et al. Roflumilast with longacting $\beta 2$-agonists for COPD: influence of exacerbation history. Eur Respir J. 2011;38(3):553-560.

31. Lee SD, Hui DS, Mahayiddin AA, et al. Roflumilast in Asian patients with COPD: a randomized placebo-controlled trial. Respirology. 2011;16(8):1249-1257.

32. Zheng J, Yang J, Zhou X, et al. Roflumilast for the treatment of COPD in an Asian population: a randomized, double-blind, parallel-group study. Chest. 2014;145(1):44-52.

33. Oba Y, Lone NA. Efficacy and safety of roflumilast in patients with chronic obstructive pulmonary disease: a systematic review and metaanalysis. Ther Adv Respir Dis. 2013;7(1):13-24.

34. Calverley PM, Martinez FJ, Fabbri LM, Goehring UM, Rabe KF. Does roflumilast decrease exacerbations in severe COPD patients not controlled by inhaled combination therapy? The REACT study protocol. Int J Chron Obstruct Pulmon Dis. 2012;7:375-382.

35. Rutten-van Mölken MP, van Nooten FE, Lindemann M, Caeser M, Calverley PM. A 1-year prospective cost-effectiveness analysis of roflumilast for the treatment of patients with severe chronic obstructive pulmonary disease. Pharmacoeconomics. 2007;25(8): 695-711.

36. Hertel N, Kotchie RW, Samyshkin Y, Radford M, Humphreys S, Jameson K. Cost-effectiveness of available treatment options for patients suffering from severe COPD in the UK: a fully incremental analysis. Int J Chron Obstruct Pulmon Dis. 2012;7:183-199. 
37. Samyshkin Y, Kotchie RW, Mörk AC, Briggs AH, Bateman ED. Cost-effectiveness of roflumilast as an add-on treatment to long-acting bronchodilators in the treatment of COPD associated with chronic bronchitis in the United Kingdom. Eur J Health Econ. 2014;15(1):69-82.

38. Perera PN, Armstrong EP, Sherrill DL, Skrepnek GH. Acute exacerbations of COPD in the United States: inpatient burden and predictors of costs and mortality. COPD. 2012;9(2):131-141.
39. Red Book Online. 2013. Available from: http://www.micromedex solutions.com/micromedex2/librarian/PFDefaultActionId/redbook. ModifyRedBookSearch. Accessed August 11, 2014.

\section{Publish your work in this journal}

Therapeutics and Clinical Risk Management is an international, peerreviewed journal of clinical therapeutics and risk management, focusing on concise rapid reporting of clinical studies in all therapeutic areas, outcomes, safety, and programs for the effective, safe, and sustained use of medicines. This journal is indexed on PubMed Central, CAS,
EMBase, Scopus and the Elsevier Bibliographic databases. The manuscript management system is completely online and includes a very quick and fair peer-review system, which is all easy to use. Visit http://www.dovepress.com/testimonials.php to read real quotes from published authors.

Submit your manuscript here: http://www.dovepress.com/therapeutics-and-clinical-risk-management-journal 